\title{
Respuesta a "Las calcificaciones simétricas y asimétricas de los ganglios basales pueden reflejar enfermedad mitocondrial"
}

\author{
Amado Jiménez-Ruiz' y José Luis Ruiz-Sandova² \\ ${ }^{1}$ Medicina Interna; ${ }^{2}$ Departamento de Neurología. Hospital Civil de Guadalajara. Guadalajara, Jalisco, México
}

Leímos con atención la carta al editor enviada por Finsterer y Maeztu' sobre el artículo "Calcificación simétrica y bilateral de ganglios basales. Serie de casos y revisión de la literatura". 2

Sabemos que el cerebro es funcional y estructuralmente asimétrico, aún en individuos sanos. ${ }^{3}$ Consideramos que las imágenes obtenidas por tomografía pueden verse discretamente asimétricas por distintos factores, incluyendo la rotación e inclinación al momento de obtener el estudio. Esto puede cambiar la forma como se aprecia la imagen para su correcta interpretación, además de otras causas como la falta de cooperación del paciente (sobre todo en neurología), impericia de los técnicos o alteración en la calibración de los sistemas de cómputo. Algunos de estos factores podrían influir en las imágenes y dar la apariencia que no son $100 \%$ idénticas, sin embargo, tienen la misma localización anatómica en ambos hemisferios.

El estudio comprendió de finales de 2012 a principios de 2016 (cuatro años) e incluyó pacientes ingresados al servicio de medicina interna para diagnóstico y que por imagen cumplían criterios de calcificación simétrica de los ganglios basales. Desconocemos el porcentaje de este hallazgo radiológico en ese periodo (2012-2016), ya que no fue el objetivo del estudio.

Los pacientes 2 y 3 no tenían otro rasgo sugestivo de enfermedad mitocondrial (historia familar, hiperlactatemia, otros trastornos endocrinos, alteraciones en ritmo cardiaco, talla baja, etcétera). En ese mismo lugar anteriormente se había efectuado una investigación de casos de síndrome de MELAS, por lo que existía sensibilidad hacia el diagnóstico diferencial. ${ }^{4}$

Lamentablemente en dicho centro no se realiza el diagnóstico molecular para citopatías mitocondriales, por lo que los casos de síndrome de MELAS fueron diagnosticados por cuadro clínico compatible, estudios de imagen y biopsia muscular con la presencia de fibras rojas rasgadas en tricrómico de Gomori.

Las citopatías mitocondriales son un grupo de enfermedades metabólicas altamente heterogéneas. Debido a la complejidad y al reto diagnóstico que representan, en el abordaje de la calcificación simétrica de los ganglios basales se debe incluir la búsqueda de estas enfermedades. ${ }^{5}$

Agradecemos los comentarios.

\section{Bibliografía}

1. Finsterer J, Maeztu C. Las calcificaciones simétricas y asimétricas de los ganglios basales pueden reflejar enfermedad mitocondrial. Gac Med Mex. 2018;154:501.

2. Jiménez-Ruiz A, Cárdenas-Sáenz O, Ruiz-Sandoval JL. Calcificación simétrica y bilateral de ganglios basales. Serie de casos y revisión de la literatura. Gac Med Mex. 2018;154:258-262.

3. Liu SX. Symmetry and asymmetry analysis and its implications to computer-aided diagnosis: a review of the literature. J Biomed Inform. 2009; 42:1056-1064.

4. Muñoz-Nevárez LA, Martín-Nares E, Ontiveros-Mercado $H$, Alvarado-Verduzco H, Valerdi-Contreras L, Ramírez-Guzmán MG. MELAS: una serie de casos del Hospital Civil de Guadalajara Fray Antonio Alcalde. Rev Endocrinol Nutr. 2013;21:138-147.

5. Finsterer J. Features on cerebral imaging suggesting mitochondrial disorder. Neurodegener Dis Manag. 2018;8:215-216.
Gac Med Mex. 2019;155:216

Disponible en PubMed www.gacetamedicademexico.com 